\title{
Aportes de Manuel Zapata Olivella en desarrollo de la novela como género literario y metarrelato educativo
}

\section{Manuel Zapata Olivella contributions in development of the novel as a literary genre and educational metanarrative}

\author{
José H. Palomo Zurique \\ Recibido: 20 de Marzo 2012. Aprobado: 25 de Abril de 2012
}

\begin{abstract}
Resumen
Esta ponencia centra su atención en dos aspectos básicos relacionados con la obra literaria del escritor colombiano Manuel Zapata Olivella. Lo primero, tiene que ver con su aporte en la transformación del canon de la novela colombiana y latinoamericana en los tiempos de la modernidad literaria. Este tópico es tratado a partir de tres novelas: Tierra mojada, La calle 10, Changó el gran putas. Lo segundo, concierne a la importancia que, como metarrelato educativo, posee el discurso literario de Zapata Olivella, específicamente en lo referido a los procesos de construcción de identidad cultural. En este sentido, se sustenta desde una mirada decolonial, su funcionalidad didáctica para estimular y propiciar procesos de construcción de identidad del ser latinoamericano, sobre todo a partir del protagonismo jugado por quienes constituyen la diáspora africana en América.
\end{abstract}

Palabras clave: Canon, modernidad literaria; novela urbana; realismo mítico; metarrelato; decolonial; identidad; diáspora.

\begin{abstract}
This paper focuses on two basic aspects of the literary work of the Colombian writer Manuel Zapata Olivella. The first has to do with his contribution to the transformation of the canon of Colombian and Latin American novel in the time of literary modernism. This topic is treated from three novels: Tierra mojada, La calle 10, Changó el gran putas.. Secondly, concerning the importance, as metanarrative educational, literary discourse has Zapata Olivella, specifically with regard to the processes of construction of cultural identity. In this sense, is based from a decolonial look, its didactic function to stimulate and foster identity construction processes of Latin American one, especially from the role played by those who are the African diaspora in America.
\end{abstract}

Keywords: Canon, literary modernity; urban novel, mythical realism, metarrelato; decolonial; Identity; Diaspora 
Manuel Zapata Olivella nació en Lorica, departamento de Córdoba, República de Colombia, el 17 de marzo de 1920. Falleció en Bogotá el 24 de noviembre del 2004. Provenía de una familia afrodescendiente. Su padre, librepensador y educador por vocación, fue aficionado a la lectura de textos filosóficos de autores franceses, representativos de la llamada época de la ilustración. Al crecer en un hogar en el que la lectura de libros, revistas y periódicos era el pan de todos los días, quizá sea lo que explique en parte la temprana inclinación de Manuel Zapata Olivella hacia las carreras de perfil humanista como la antropología y la medicina y, por supuesto, hacia la literatura.

En esta ocasión, me referiré a un aspecto básico relacionado con la obra literaria de este consagrado escritor colombiano y, para mayor orgullo nuestro, afrocaribeño, sinuano, cordobés, loriquero. Se trata de sus aportes a la transformación del canon de la novela colombiana y latinoamericana y a la función educativa que cumplen sus novelas como metarrelatos recreadores de la visión del mundo de quienes encarnan la diáspora africana en América. Para ello, tomaré como puntos de referencia tres de sus novelas: Tierra mojada, La calle 10 y Changó, el gran putas.

En cuanto a referentes teóricos, me apoyé en las ideas de canon literario, ideologema, modernidad, novela urbana, expuestas por Álvaro Pineda Botero en su libro El reto de la crítica. Respecto a la noción de canon literario, además de Pineda Botero, he recurrido a planteamientos de Henry Louis Gates expresadas en su ensayo Las obras del amo: sobre la formación del canon y la tradición afroamericana, que hace parte del libro El canon literario, compilado por Enric Sullá.

La idea de metarrelato es entendida en esta ponencia no como los grandes discursos que sustentan y buscan conservar y prolongar en el tiempo el poder (político, económico, religioso, filosófico, estético, ético, etc) de las clases sociales que gobiernan las naciones y sociedades occidentales modernas, discursos que en el contexto literario recrean las utopías de salvación colectiva y de desarrollo integral de la humanidad y, como tal, constituyen metáforas de la realidad. De acuerdo con Lyotard (1989) los metarrelatos son "discursos totalizantes y multiabarcadores, en los que se asume la comprensión de hechos de carácter científico, histórico y social de forma absolutista, pretendiendo dar respuesta y solución a 
toda contingencia”. El filósofo francés considera inconsistente este concepto de metarrelato defendido por los teóricos euroccidentales de la estética moderna, porque "se contradice a sí mismo al intentar crear una visión absolutista, sistematizada y totalizante como trascendente y universalizadora de toda metanarrativa". En este sentido, la mayoría de los críticos y creadores literarios latinoamericanos se convirtieron en epígonos de los modelos literarios euroccidentales recreando los metarrelatos que idealizan el modelo de vida capitalista y el llamado "socialismo real", este último, derrumbado estrepitosamente en la década de los años 80 del siglo pasado.

Sin embargo, los metarrelatos que recrean los modelos de conocimiento y conciben la historia desde perspectivas epistémicas euroccidentales, no son los únicos que tienen cabida en los textos literarios. También existen metarrelatos alternativos que pedagógica y didácticamente podrían ser funcionales en el campo educativo en la medida en que están fundamentados en un pensamiento heterárquico, que de acuerdo con Grosfoguel, citado por Dairo Sánchez (2007)) "contemplan el mundo y las esencias de las cosas desde posiciones independientes, ofreciendo sorprendentes soluciones a los interminables problemas humanos". Uno de estos metarrelatos alternativos es el que hoy se denomina decolonialidad o discurso decolonialista, que Grosfoguel (Sánchez: 2007) plantea como "un proceso de resignificación a largo plazo, que no se puede reducir a un acontecimiento jurídicopolítico".

Una manera de contribuir al posicionamiento y divulgación del pensamiento decolonial, eminentemente heterárquico, es desarrollando "un nuevo lenguaje que dé cuenta de los complejos procesos del sistema-mundo capitalista/patriarcal moderno/colonial sin depender del viejo lenguaje de las ciencias sociales decimonónicas" (Castro Cómez y Grasfoguel: 2007) Para estos investigadores, la elaboración de un lenguaje que exprese esta complejidad implica:

buscar afuera de nuestros paradigmas, enfoques, disciplinas y campos de conocimiento (...) entrar en diálogo con formas no occidentales de conocimiento que ven el mundo como una totalidad en la que todo está relacionado con todo, pero también con las nuevas teorías de la complejidad (pensamiento heterárquico) (2007).

Poligramas 37, primer semestre 2013, ISSN 0120-4130. 
Sánchez, apoyándose en Gómez y Grasfoguel (2007) afirma que lo decolonial es: un lenguaje capaz de pensar los sistemas de poder como una serie de dispositivos heterónomos vinculados en red (...) que expresa un pensamiento heterárquico, el cual trasciende el lenguaje del paradigma de la dependencia.

La literatura es, precisamente, uno de los territorios estéticos más fértiles para cultivar y divulgar la perspectiva discursiva decolonial, el pensamiento heterárquico. En el caso de la literatura latinoamericana, existe desde los tiempos de la Colonia una tradición heterárquica que nos muestra desde visiones aborígenes y desde la diáspora africana formas de soñar el mundo, vivirlo, interpretarlo, concebirlo, inventarlo y reinventarlo que se distancian de los criterios epistémicos eurocéntricos. En lo que respecta a la diáspora africana, esa tradición libertaria, autonómica, se manifiesta desde que llegó a América (siglo XVI). Tal vez empezó con el pacto de Boy Caimán, manifestándose en canciones y rituales que se inventaron para comunicarse en sus lenguas ancestrales los santos y señas de sus acciones rebeldes, libertarias y que sus amos europeos creían que eran meras pantomimas de carnaval. Continuó con la creación de los Palenques, comunidades independientes conformadas por negros cimarrones, que desafiaron el sojuzgamiento colonial, como la fundada por el legendario Benkos Biojó en la costa Caribe colombiana, concretamente en las estribaciones de los montes de María en el Departamento de Bolívar. Y más tarde se proyectaría en las gestas independentistas que dieron origen a las modernas naciones de América, en las que el "muntu americano", el hombre afrodescendiente, jugó un protagonismo determinante. Sin embargo, todavía hoy la mayor parte de los manuales de historia nacional y continental que se usan en las escuelas para educar en la reafirmación de la identidad de nuestros pueblos ignoran esa participación destacada de la corriente cultural afroamericana en la fundación y consolidación de las naciones americanas modernas. En este sentido, es la literatura afroamericana la que se ha propuesto la misión de no dejar naufragar en el mar del olvido el aporte decisivo de la diáspora africana en la creación y sostenibilidad política, económica y cultural de las naciones que hoy conforman nuestra América. 
Novelas como Changó, el gran putas del colombiano Manuel Zapata Olivella, no solo sirven para sustentar esta afirmación sino también para defender la funcionalidad del texto literario como metarrelato educativo en la medida en que expresa un discurso heterárquico o decolonial que podría servir como recurso didáctico para agenciar procesos de construcción y reafirmación de identidad del ser americano. Al menos, esta es la tesis que intentaré sustentar en la presente ponencia.

\section{El canon de la novela colombiana y latinoamericana a principios del siglo XX}

Manuel Zapata Olivella fue uno de los primeros escritores del Caribe colombiano que antes de finalizar la primera mitad del siglo XX se atrevió a desafiar el canon de la novela imperante en Colombia y en el resto de Latinoamérica, que para entonces se caracterizaba por ser obediente a los moldes de la estética clásica, procedente de Europa Occidental. Este desafío se manifestó en varios ámbitos: primero, en el terreno de los ideologemas; segundo, en la focalización de los avatares de la vida urbana como tema literario; tercero, en las innovaciones estilísticas del género novela.

Quienes hayan estudiado la historia de la literatura colombiana y en particular, la del género novela, seguramente sabrán que el canon imperante hasta la primera mitad del siglo $\mathrm{XX}$ se caracterizaba por un lenguaje de tendencia dominantemente monológica, en el que los personajes eran objetos de discurso y no sujetos discursivos. Dominaba el narrador omnisciente, el cual era, casi siempre, portador de un léxico académico, que reproducía la visión del mundo y los intereses ideológicos de la cultura oficial o políticamente dominante, defensora abierta y sutil de los intereses de la burguesía terrateniente. Para ese tiempo, los paradigmas de novela en Colombia y en gran parte de Latinoamérica eran María de Jorge Isaac y La vorágine de José Eustasio Rivera. En la primera, publicada en 1867, domina una visión romántica, bastante idealizada del paisaje y de las relaciones entre patronos y trabajadores, gobernantes y gobernados, padres e hijos, etc. En la segunda, publicada en 1924, ya se percibe abiertamente un grado de ruptura o distanciamiento con los ideologemas reproductores de las ideologías y culturas patriarcales, las cuales funcionaban como alicientes para mantener y defender los intereses económicos, sociales y

Poligramas 37, primer semestre 2013, ISSN 0120-4130. 
políticos de las élites burguesas y terratenientes de Colombia y el resto del continente americano. En el caso de La vorágine, los ideologemas dominantes dejan ver ante todo la visión del mundo del intelectual pequeñoburgués, del hombre de clase media, de espíritu aventurero encarnado en el personaje Arturo Cova, un ser cargado de sueños y utopías que afanosamente buscaba transformar la realidad o el mundo en el que vivía, pero desde una perspectiva individualista.

Tierra mojada, la primera novela de Zapata Olivella, publicada en 1947, viene a ser un hipertexto de La vorágine, en la medida en que es un texto posterior al de Rivera en el que también se expresa un discurso salpicado de ideologemas contestatarios contra las ideologías burguesa-terratenientes y contra las culturas patriarcales impuestas en América por las fuerzas colonialistas provenientes de Europa Occidental. Los protagonistas y el narrador dominante de Tierra mojada son portadores de utopías y sueños de transformación del mundo, pero a diferencia de la novela de José Eustasio Rivera, la utopía de cambio recreada en la novela de Zapata Olivella trasciende las fronteras de la búsqueda individualista y se convierte en la expresión de un proyecto colectivo, un sueño de comunidad cultural, la de los campesinos del Sinú, los desposeídos de la tierra, o como les llaman ahora, desplazados.

Tierra mojada, al igual que La vorágine, es una novela terrígena porque predomina en ella una visión nativista, tejida por relaciones actanciales que expresan la fusión idealizada entre hombre y naturaleza, hombre y paisaje. En ambas novelas, la tierra, la selva, el río, el mar se convierten en personajes protagonistas de la narración. Tales elementos, al funcionar como actantes, no son neutrales. A lo largo de la diégesis narrativa, toman partido por los desposeídos, los desplazados, los que son víctimas de injusticias sociales. Así las cosas, en Tierra mojada el hombre y su entorno natural, constituyen una sola fuerza, un solo organismo.

A diferencia de La vorágine, en Tierra mojada no se idealiza tanto a los protagonistas; impera una visión menos romántica y más realista del mundo, posee un tono de autocrítica bastante protuberante que no se nota en La vorágine o si este fenómeno también existe en la novela de Rivera, es menos perceptible. En este sentido, personajes como el Goyo y

Poligramas 37, primer semestre 2013, ISSN 0120-4130. 
Estebana son más redondos que planos porque la dimensión sicológica, ética y estética que los configura como seres pensantes y actuantes no es unidireccional, ni estática. Ellos también son como el río, de un andar sinuoso, temperamentales, se crecen y se bajan en cualquier momento; son como las olas del mar que van y vienen y no se mantienen quietas en ningún punto. Estos rasgos que caracterizan a los personajes de Tierra mojada se convierten, a mi juicio, en uno de los aportes estéticos más significativos en la transformación del canon novelístico colombiano a mediados del siglo XX, especialmente porque supera la tendencia estética e ideológica dominante en la novela de ese período, que ante todo, reproduce los intereses de las culturas patriarcales. La novela de Zapata Olivella, por el contrario, incursiona en el territorio narrativo de tono internamente dialógico aunque sea todavía en las fronteras de un solo sujeto discursivo.

\section{La novela urbana en Colombia:}

Una segunda contribución de Zapata Olivella a la transformación del canon novelístico en Colombia, se da en 1952, al publicar La calle 10. Esta novela es una de las pioneras en nuestro país en cuanto a la recreación de los conflictos sociales en el contexto cultural urbano y configuración estética, ética y sicológica de los personajes. Lo que se relata en ese texto literario sucede en el corazón de Bogotá, la ciudad más cosmopolita del país, la Bogotá del siglo XX, la del tiempo de la modernidad. En La calle 10 se expresa de una manera impactante el drama humano de la descomposición moral imperante en los espacios urbanos, con una clara intención de denuncia social. Con novelas como la referenciada, Manuel Zapata Olivella afianza su ingreso a la modernidad literaria, no sólo porque recrea el espacio urbano, elemento este que es más contingencial que esencial en la determinación estilística de esta variante de género, llamada novela urbana, sino porque construye sicológicamente sus personajes empleando criterios estéticos de verosimilitud, muy cercanos al modo de sentir y actuar de las personas que social y culturalmente habitan e interactúan en los espacios urbanos. Refiriéndose a los rasgos innovadores en el plano de la técnica narrativa, que Zapata Olivella emplea en La calle 10, John Brushwood, profesor emérito de la Universidad de Kansas, afirmó en el prólogo de la mencionada novela: 
El novelista emplea una combinación de caracterizaciones bien individualizadas y la proyección de una masa insurrecta para comunicar el aspecto íntimo y el aspecto público de la crisis. Cambia escenas cinematográficamente pero con una intercalación suficiente para crear un sentido de unidad. Proyecta el tono de urgencia mediante un lenguaje sencillo, directo, pero que revela cierta ternura al referirse a la gente. La técnica narrativa, en esta novela, es más innovadora que la de muchas novelas del mismo autor.

Por su parte, el crítico colombiano Cesar Valencia Solanilla (1993) refiriéndose a la novela urbana en Colombia, señala que la singularidad de ésta:

no está simplemente por la recreación de un paisaje o ambientes citadinos, sino por la concurrencia de una especie de atmosfera interior, de estado síquico de los personajes propios del anonimato, la soledad, el desarraigo y la quiebra espiritual de las grandes urbes contemporáneas, en donde el hombre pierde cada vez más su identidad y pasa a ser un elemento indeterminado relativamente útil para el engranaje social dominado por la tecnología y la abstracción.

Esa atmosfera interior, escalofriante, cruda, a la cual se refiere Valencia Solanilla, es la que precisamente conmueve y atrapa al lector en La calle 10 del afrocaribeño Zapata Olivella.

Por ello, no quisiera creer que estudiosos de la literatura colombiana, caracterizados por ser exhaustivos en sus trabajos de investigación, como los convocados por el Ministerio de Cultura para que prepararan y redactaran el Manual de Literatura Colombiana que todavía hoy circula en todo el país y es texto de consulta obligada en los cursos de literatura y en las bibliotecas de universidades e instituciones educativas de nivel básico y medio, hayan obviado intencionalmente la referencia a La calle 10 como una de las primeras novelas urbanas escritas y publicadas en Colombia. Es cierto que antes de ser publicada la novela de Zapata Olivella, ya se conocían algunas obras literarias que recrean el mundo urbano y personajes de sicología urbana, entre estas, podría mencionarse Cuatro años a bordo de mí mismo de Eduardo Zalamea, publicada en 1934; Mancha de aceite de César Uribe Piedrahita, publicada en 1935. Esta última, más que una novela propiamente dicha, es una crónica autobiográfica, en la que se recrean paisajes y sicologías de personajes provenientes del mundo urbano, los cuales interactúan en contextos rurales y semiurbanos. Igual sucede con la primera novela aludida, Cuatro años a bordo de mí mismo, en la que impera como cronotopo el camino y los espacios urbanos de ciudades como Barranquilla y pueblos semiurbanos como Puerto Colombia en el Atlántico y Bahía honda en la Guajira. Esas novelas, al igual que la de Zapata Olivella, tuvieron una circulación restringida que no 
trascendió los círculos lectores de Bogotá y Medellín. No obstante, son las que todavía la crítica literaria en nuestro país reconoce como representativas y pioneras de la novela urbana en Colombia.

De estos intentos de novela urbana de los años 30, los estudiosos del tema, en la mayoría de los casos, dan un salto hasta la década del 70, tiempo en que el caleño Andrés Caicedo publica Qué viva la música. En esos estudios críticos no se hace alusión alguna a La calle 10 publicada a principios de los años 50, es decir, dos décadas antes que circulara la interesante novela corta de Caicedo.

Olvidos como el sucedido con la novela urbana de Zapata Olivella, nos recuerdan que cada generación está obligada a actualizar la historia. Aportes como el que hace este escritor afrocolombiano al desarrollo de la novela urbana en Colombia, no pueden seguir ignorándose y es deber de las nuevas generaciones de historiadores y estudiosos de la literatura regional, nacional y continental reescribir la historia, actualizarla. Este trabajo, que hoy tengo la oportunidad de compartir con ustedes, es una humilde contribución para responder afirmativamente a ese reto histórico.

Un tercer aporte de Zapata Olivella a la transformación del canon novelístico, está representado en su novela Changó, el gran putas, publicada en 1983. Este texto literario, más que una novela, es la gran epopeya de la diáspora africana en América, es un inmenso poema épico en el que artísticamente se conjuga la prosa narrativa y el verso lírico. Este texto, no sólo es la obra cumbre de Zapata Olivella, sino el aporte más significativo en la actualización del canon de la novela épica en los tiempos de la modernidad. En términos de innovación estética, Changó, el gran putas llega tan o más lejos que muchas de las obras creadas por reconocidos escritores latinoamericanos que antecedieron a Zapata Olivella. En este sentido, aludo a obras como Señor Presidente, Hombres de maíz, Leyendas de Guatemala del guatemalteco Miguel Ángel Asturias, Premio Nobel en 1962; La serpiente de oro, El mundo es ancho y ajeno, Los perros hambrientos del peruano Ciro Alegría; "Huasipungo" del ecuatoriano Jorge Icaza, las cuales se ganaron merecidamente un sitio destacado en el canon novelístico de la literatura hispanoamericana por su riqueza temática y estético estilística.

Poligramas 37, primer semestre 2013, ISSN 0120-4130. 


\section{El significado de Changó, el gran putas}

Changó, el gran putas, es un texto narrativo, alterador del canon novelístico latinoamericano, tanto por la temática focalizada, como por los recursos estéticos empleados en la estructuración del lenguaje que le da forma. En cuanto a lo primero, trata el fenómeno de la identidad del ser americano desde una mirada decolonial, principalmente resaltando el protagonismo político, ideológico, estético, ético de la corriente cultural que gestó a América y la ingresó en la modernidad, la del muntu, la de los hijos de Changó y Yemayá.

En esta novela, mito e historia se conjugan para rescatar la memoria colectiva, es el relato épico de la creación de los pueblos y naciones de América contada por sus protagonistas, los negros y mulatos que encarnan la diáspora africana en América. Sin demeritar el valor estético y educativo de las demás novelas y textos literarios de Zapata Olivella, Changó, el gran putas constituye el mayor aporte en términos de metarrelato educativo que se hace desde la literatura al conocimiento del protagonismo de la corriente cultural afroamericana en la fundación de las naciones de América, historia contada desde una mirada no eurocéntrica.

Desde perspectivas miméticas y diegéticas, la novela relata el mítico e histórico viaje de los africanos a tierras americanas, describe el origen mítico de las etnias africanas, el tratamiento de esclavos que recibieron durante el período colonial, el viacrucis del largo viaje desde las costas africanas hasta tierras americanas, las formas del mestizaje cultural después de llegar y aclimatarse en América, el aporte del ser mulato en las gestas de liberación e independencia y la participación de los herederos de Changó en los procesos de democratización y desarrollo tecnológico en los tiempos contemporáneos. Por ello, no vacilo en exhortar a los editores de libros presentes en este evento, para que se interesen en reeditar esta portentosa novela y de esa manera, contribuyan a divulgar el pensamiento heterárquico proveniente de una corriente cultural

Poligramas 37, primer semestre 2013, ISSN 0120-4130. 
no occidental, pero que tampoco desconoce las contribuciones euroccidentales, pues este tipo de pensamiento no es excluyente, sino inclusivo, integrador y, como tal, nos brinda una mirada diferente de lo que es el negro americano, de lo que es la historia de los pueblos de nuestra América.

En cuanto a lo segundo, impera en Changó, el gran putas el tiempo del mito, que corresponde a un movimiento cíclico y en espiral. Ello permite que los seres míticos (orichas) habiten el mismo espacio de los seres históricos, que vivos y muertos dialoguen e interactúen en el mismo mundo. Por la forma como está escrita, esta novela es totalizadora e integradora de los mundos gestados y habitados por el ser afroamericano. Estas características estético-estilísticas son las que permiten afirmar que con Changó, el gran putas, Manuel Zapata Olivella llevó el realismo mítico a su más alta cumbre como tendencia estilística en la narrativa latinoamericana. Dicho de otra manera, si nuestro premio Nobel, Gabriel García Márquez, se consagró como catapultador del realismo mágico con Cien años de soledad y El otoño del patriarca, nuestro Ekobio Mayor, Manuel Zapata Olivella, se consagró como el catapultador del realismo mítico en Changó, el gran putas, llevándolo a las más altas cumbres de la literatura continental y mundial.

En Changó, el gran putas se fusionan diversos géneros discursivos. Por consiguiente, es una novela rica en intertextualidad, abiertamente crítica y autocrítica, es la condensación de la historia reescrita por sus protagonistas. Estos rasgos hacen que la novela de Zapata Olivella adquiera un tono fuertemente polifónico, que nos habla no sólo del pasado sino de nuestro presente, de las utopías del muntu, del ser mulato americano, no tanto como individuo, sino ante todo como etnia, como comunidad cultural, como pueblo, recordándonos que existe desde los tiempos prehistóricos, valga decir, desde los tiempos del mito, una ruta, un camino, aún inconcluso, desbrozado con amor, dolor y sangre, por donde se puede seguir avanzando en la construcción y consolidación de la identidad americana.

Son estos aportes, los que permiten afirmar que Manuel Zapata Olivella es uno de los escritores afrocolombianos que más ha contribuido a la transformación del canon novelístico en la literatura colombiana y latinoamericana desde mediados del siglo XX. Es también lo que justifica que estudiemos y exaltemos su obra literaria en eventos como el 
que en estos días nos convoca, la X Jornada Andina de Literatura Latinoamericana JALLA 2012.

\section{Bibliografía}

Rodrigo Argüello. La muerte del relato metafísico. Si Editores, Bogotá, 1992

Mijail Bajtín. Estética de la creación verbal. Siglo XXI Editores, Bogotá, 1988

............... Teoría y estética de la novela. Taurus, Alfaguara, Madrid, 1989

Jean Francois Lyotard. La condición posmoderna. Ediciones Cátedra, Madrid, 1986

Álvaro Pineda Botero. El reto de la crítica. Planeta, Bogotá, 1995

.............................. Del mito a la posmodernidad: la novela colombiana de

finales del siglo XX. La novela colombiana ante la crítica. Editorial Facultad de Humanidades Universidad del Valle, Centro Editorial Javeriano CEJA, Cali, 1994

Mario Enrique Rey. Una mirada a la obra de Manuel Zapata Olivella. La novela colombiana ante la crítica. Editorial Facultad de Humanidades Universidad del Valle, Centro Editorial Javeriano CEJA, Cali, 1994

Dairo Andrés Sánchez Mojica. Reseña de El giro decolonial. Reflexiones para una diversidad epistémica más allá del capitalismo global de Santiago Castro-Gómez y Ramón Grosfoguel (Eds.). Nómadas (Col) [en línea] 2007, [citado 2012-07-07]. Disponible en Internet: http://redalyc.uaemex.mx/src/inicio/ArtPdfRed.jsp?iCve=105116595019. ISSN 0121-7550.

Cesar Valencia Solanilla. La novela colombiana contemporánea en la modernidad literaria. Manual de literatura colombiana, tomo II. Planeta, Procultura, Bogotá, 1993 
Manuel Zapata Olivella. Changó, el gran putas. Oveja negra, Bogotá, 1983

.............................La calle 10. Prolibros Ltda, Bogotá, 1986

.Tierra mojada. Bedout, Medellín, 1982

Enric Zullá. El canon literario. Arco/Libros, Madrid, 1998 